\title{
Respiratory Distress Syndrome in Full-term Neonates
}

\section{Jing Liu*}

Department of Neonatology \&NICU, Bayi Children's Hospital Affiliated with General Hospital of Beijing Military Command, Beijing 100700, China

Respiratory distress syndrome (RDS) is one of the most common causes of neonatal respiratory failure and neonatal death. It was believed that RDS is mainly found in premature infants, the risk of developing into RDS increased with decreasing of gestational age and birth weight; the incidence rate is $80 \%$ in infants $<28$ weeks gestation, $60 \%$ at 29 weeks, and $15-30 \%$ at $32-34$ weeks, but declined with maturity to $5 \%$ at $35-36$ weeks and is almost $0 \%$ by 39 weeks gestation [1].Accordingly, it is estimated that the incidence rate of RDS is at $80 \%$ for infants weighing $<750 \mathrm{~g}$ at birth and $55 \%$ for infants weighing $750-1000 \mathrm{~g}$ [2]. However, greater awareness of RDS has led to its more frequent diagnosis in term neonates [3-5], such as Bouziri et al. [4] found that RDS accounted for $6.8 \%$ of cases of respiratory distress in term or near-term infants. However, the clinical characteristics, diagnostic criteria and treatment strategies of term neonatal RDS are very different from that in premature infants, all of these will be discussed here.

\section{Possible Causes}

The possible reasons associated with full-term neonatal RDS may be as following: (1) Severe perinatal acquired infections (severe pneumonia and/or septicemia): this is the most common cause of term neonatal RDS. (2) Elective caesarean sections: it has been well documented that the increasing risk of serious respiratory morbidity was associated with decreasing gestational age [6]. It has been suggested that relative surfactant deficiency was the main cause of RDS in elective caesarean birth infants, because of their relatively early gestational age. (3) Severe birth asphyxia and meconium aspiration syndrome (MAS). (4) Pulmonary hemorrhage. (5) Inherited disorders of surfactant metabolism are a rare cause of respiratory disease in newborns but are associated with significant morbidity and mortality [7].

\section{Classification for Term Neonatal RDS}

Full-term neonatal RDS can be divided into three types, they are as following: (1) Acute respiratory distress syndrome (ARDS): which follows a catastrophic pulmonary or non-pulmonary event, such as asphyxia, meconium aspiration, shock, sepsis and disseminated intravascular coagulation. (2) Idiopathic respiratory distress syndrome (IRDS): Mainly was seen in selective cesarean section babies. The earlier the cesarean section was performed, the higher the incidence of RDS in full-term neonates was [6,8-10]. (3) RDS with relating to inherited surfactant disorders: Inherited disorders of surfactant metabolism is a rare condition but associated with significant morbidity and mortality $[11,12]$.

\section{Clinical Characteristics}

(1) Severe perinatally acquired infection (pneumonia/septicemia) is the most common cause of full-term neonatal RDS, and the second reason is selective cesarean section.

(2) Full-term neonatal RDS is more common in boys than in girls (almost 3 times more frequent in boys).

(3) The onset of the disease in term neonates is earlier, the illness states is more severe and processes more rapidly and is more likely to result in PPHN and MOSF.
(4) Most patients require prolonged mechanical ventilation, the majority of the patients needed 7-10 days; mechanical ventilation could only be withdrawn within 7 days in a minority.

(5) The mortality was higher, the main cause of death was severe infection complicating of MOSF.

\section{Diagnostic Criteria}

Several criteria for the diagnosis of RDS in full-term neonates have been suggested. Bouziri et al. [3] diagnosed RDS based on the following criteria: (1) Gestational age $\geq 35$ weeks; (2) Severe and immediate respiratory distress requiring mechanical ventilation with $\mathrm{PEEP} \geq 4 \mathrm{~cm} \mathrm{H} \mathrm{H}_{2} \mathrm{O}$ and $\mathrm{FiO}_{2} \geq 0.5$ during at least 6 hours; (3) Dependence on oxygen $\geq 48$ hours; (4) Diffuse alveolar damage shown by chest radiography; (5) $\mathrm{PaO}_{2} \leq 60 \mathrm{mmHg}$ under $\mathrm{FiO}_{2} \geq 0$. . Faix et al. [4] applied the following criteria to neonates: (1) They were full term by obstetric and neonatal criteria; (2) They had diffuse bilateral alveolar opacification on chest radiographs during the acute illness; (3) Each of them had an acute perinatal triggering insult; (4) They required continuous positive pressure ventilation for at least 48 hours with $\mathrm{FiO}_{2}$ $>0.50$ for at least 12 hours; (5) They needed positive end-expiratory pressure of $\geq 6 \mathrm{~cm}$ of $\mathrm{H}_{2} \mathrm{O}$ within 3 days of the triggering event; and (6) There were no other known causes for these clinical conditions. Based on our clinical experiences, together with the diagnostic criteria for premature infants and adults, we suggest the following criteria for diagnosis of full-term neonatal RDS [13]: (1) Acute onset; (2) Had an acute explicit perinatal triggering insult: such as severe perinatally acquired infection, elective cesarean section, severe birth asphyxia, meconium aspiration syndrome, etc.(3) Representative clinical manifestations including progressive respiratory distress occurring shortly after birth, characteristic grunting respiration, retractions during inspiration, cyanosis, and reduced or absent breathing sounds; (4) Typical chest x-ray findings, which including hypoexpansion and diffuse, fine granular densities (grade I), air bronchograms caused by the atelectatic air sacs (grade II), ground-glass appearance (grade III) or white lungs caused by diffuse bilateral atelectasis (grade IV); (5) Arterial blood gas analysis showing hypoxia, hypercapnia and oxygen tension/fraction of inspired oxygen ratio $\left(\mathrm{PaO}_{2} / \mathrm{FiO}_{2}\right) \leq 26.7 \mathrm{kPa}$.

\section{Treatment Strategies}

(1) Broad spectrum antibiotics: Because perinatal acquired infection is the leading cause of term neonatal RDS, thus any patient with RDS should be given broad spectrum antibiotics as soon as

*Corresponding author: Jing Liu, Department of Neonatology \& NICU, Bayi Children's Hospital Affiliated With General Hospital of Beijing Military Command, 5 Nanmen Cang, Beijing 100700, China, Tel: 86-10-66721257; Fax: 8610-66721257; E-mail: Liujingbj@live.cn

Received June 11, 2012; Accepted June 11, 2012; Published June 13, 2012

Citation: Liu J (2012) Respiratory Distress Syndrome in Full-term Neonates. J Neonatal Bio S1:e001. doi:10.4172/2167-0897.S1-e001

Copyright: (c) 2012 Liu J. This is an open-access article distributed under the terms of the Creative Commons Attribution License, which permits unrestricted use, distribution, and reproduction in any medium, provided the original author and source are credited. 
possible after diagnosis was made. (2) Mechanical ventilatory support: Mechanical ventilation is the most important measure for ensuring a successful outcome, and assisted ventilation should be administered to every patient once a diagnosis is made; nasal continuous positive airway pressure (nCPAP) is not adequate for treating RDS in fullterm infants, and this is very different from premature infants with RDS [14]. (3) Supplement of exogenous surfactant: Exogenous lung surfactant is very important for the treatment of full-term neonatal RDS and should be given as soon as possible after diagnosis is made. We use Calsurf (one kind of exogenous pulmonary surfactant, made in Beijing Double-Crane Pharmaceutical Co., Ltd, China) getting an ideal results which can improve gas exchange and oxygenation, decreases the need for ventilatory support and shortens hospitalization time, and has no risk of transmitting infections or causing immunologic sensitization [15]. (4) i-NO therapy: PPHN is one kind of common complication of tern neonatal RDS, thus i-NO is often need to be used in these patients.(5) Prophylaxis and treatment of myocardial injury: Myocardial injury including myocardial infarction, ventricular flutter or fibrillation is an important cause of death, therefore prophylaxis and treatment of myocardial injury in full-term infants with RDS is important, once RDS is diagnosed, various drugs such as creatine phosphate sodium, sodium fructose diphosphate, and high-doses of vitamin $\mathrm{C}$ can be used for this purpose. (6) Other treatments: Patients with inherited surfactant disorders often develop severe respiratory failure immediately after birth, and surfactant replacement therapy is not useful in these circumstances. Extracorporeal membrane oxygenation should be used in these cases and pulmonary transplantation should be performed as soon as possible, otherwise all patients die within the first year of life.

In a word, RDS is a common severe disease in full-term neonates, it is important to understand its clinical characteristics, diagnostic criteria and treatment strategies for improving the prognosis of these babies.

\section{Acknowledgments}

This work was support by CJP-Kelisu Research Funding (cjp2011005).

\section{References}

1. Hansen T, Corbet A (1999) Disorder of the transition. In Taeusch HW, Ballard RA, Avery's Diseases of the Newborn.7th Edition, USA, Harcourt Publisher Limited: 602-629.
2. Koivisto $M$, Marttila $R$, Kurkinen-Raty $M$, Saarela $T$, Pokela $M L$ et al. (2004) Changing incidence and outcome of infants with respiratory distress syndrome in the 1990s: a population-based survey. Acta Paediatr 93:177184

3. Ayachi A, Rigourd V, Kieffer F, Dommergues MA, Voyer M et al. (2005) [Hyaline membrane disease in full-term neonates]. Arch Pediatr 12: 156-159.

4. Bouziri A, Ben Slima S, Hamdi A, Menif K, Belhadj S et al. (2007) [Acute respiratory distress syndrome in infants at term and near term about 23 cases]. Tunis Med 85: 874-879.

5. Faix RG, Viscardi RM, DiPietro MA, Nicks JJ (1989) Adult respiratory distress syndrome in full-term newborns. Pediatirics 83:971-976.

6. Hansen AK, Wisborg K, Uldbjerg N, Henriksen TB (2008) Risk of respiratory morbidity in term infants delivered by elective caesarean section: cohor study. BMJ 336:85-87.

7. Gower WA, Wert SE, Nogee LM (2008) Inherited Surfactant Disorders. NeoReviews 9: e458-e467.

8. Tita AT, Lai Y, Landon MB, Spong CY, Leveno KJ et al. (2011) Timing of elective repeat cesarean delivery at term and maternal perioperative outcomes. Obstet Gynecol 117:280 -286.

9. Farchi S, Di Lallo D, Polo A, Franco F, Lucchini R, et al. (2010) Timing of repeat elective caesarean delivery and neonatal respiratory outcomes. Arch Dis Child Fetal Neonatal Ed 95: F78.

10. Robinson CJ, Villers MS, Johnson DD, Simpson KN (2010) Timing of elective repeat cesarean delivery at term and neonatal outcomes: a cost analysis. Am J Obstet Gynecol 202: 632.e1-6.

11. Hamvas A, Cole FS, Nogee LM (2007) Genetic disorders of surfactant proteins. Neonatology 91: 311-317.

12. Nkadi PO, Merritt TA, Pillers DA (2009) An overview of pulmonary surfactant in the neonate: genetics, metabolism, and the role of surfactant in health and disease. Mol Genet Metab 97: 95-101

13. Liu J, Shi Y, Dong JY, Zheng T, Li JY, et al. (2010) Clinical characteristics, diagnosis and management of respiratory distress syndrome in full-term neonates. Chin Med J(Engl) 123: 2640-2644

14. Sweet DG, Carnielli V, Greisen G, Hallman M, Ozek E, et al. (2010) European consensus guidelines on the management of neonatal respiratory distress syndrome in preterm infants - 2010 update. Neonatology 97: 402-417.

15. Shi Y, Yang N, Liu J, Xu J, Zheng T (2011) Domestic pulmonary surfactantCalsurf on the treatment of respiratory distress syndrome in full-term neonates. Modern Medicine Journal of China 13:9-12. 